\title{
2019 HRS/EHRA/APHRS/LAHRS focused update to 2015 expert consensus statement on optimal implantable cardioverter-defibrillator programming and testing
}

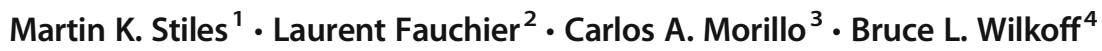 \\ Published online: 21 January 2020 \\ (C) The Heart Rhythm Society; the European Heart Rhythm Association, a registered branch of the European Society of Cardiology; the Asia Pacific Heart \\ Rhythm Society; and the Latin American Heart Rhythm Society 2020
}

\begin{abstract}
The 2015 HRS/EHRA/APHRS/SOLAECE Expert Consensus Statement on Optimal Implantable Cardioverter-Defibrillator Programming and Testing provided guidance on bradycardia programming, tachycardia detection, tachycardia therapy, and defibrillation testing for implantable cardioverter-defibrillator (ICD) patient treatment. The 32 recommendations represented the consensus opinion of the writing group, graded by Class of Recommendation and Level of Evidence. In addition, Appendix B provided manufacturer-specific translations of these recommendations into clinical practice consistent with the recommendations within the parent document. In some instances, programming guided by quality evidence gained from studies performed in devices from some manufacturers was translated such that this programming was approximated in another manufacturer's ICD programming settings. The authors found that the data, although not formally tested, were strong, consistent, and generalizable beyond the specific manufacturer and model of ICD. As expected, because these recommendations represented strategic choices to balance risks, there have been reports in which adverse outcomes were documented with ICDs programmed to Appendix B recommendations. The recommendations have been reviewed and updated to minimize such adverse events. Notably, patients who do not receive unnecessary ICD therapy are not aware of being spared potential harm, whereas patients in whom their ICD failed to treat life-threatening arrhythmias have their event recorded in detail. The revised recommendations employ the principle that the randomized trials and large registry data should guide programming more than anecdotal evidence. These recommendations should not replace the opinion of the treating physician who has considered the patient's clinical status and desired outcome via a shared clinical decision-making process.
\end{abstract}

Keywords Antitachycardia pacing - Bradycardia mode and rate · Defibrillation testing - Implantable cardioverter-defibrillator . Programming $\cdot$ Sudden cardiac death $\cdot$ Tachycardia detection · Tachycardia therapy $\cdot$ Ventricular tachycardia $\cdot$ Ventricular fibrillation

Published by Elsevier Inc./ Oxford University Press/Wiley. This article is published under the Creative Commons CC-BY license.

Martin K. Stiles is the Chair. He is the Representative of the Asia Pacific Heart Rhythm Society (APHRS)

Laurent Fauchier is the Representative of the European Heart Rhythm Association (EHRA)

Carlos A. Morillo is the Representative of the Latin American Heart Rhythm Society (LAHRS)

Bruce L.Wilkoff is the Representative of the Heart Rhythm Society (HRS)

Developed in partnership with and endorsed by the European Heart Rhythm Association (EHRA), the Asia Pacific Heart Rhythm Society (APHRS), and the Latin American Heart Rhythm Society (LAHRS). For copies of this

Heart Rhythm Society

clinicaldocs@hrsonline.org

1 Waikato Hospital, Hamilton, New Zealand

2 Centre Hospitalier Universitaire Trousseau, Université François Rabelais, Tours, France document, please contact the Elsevier Inc. Reprint Department (reprints@elsevier.com). Permissions: Multiple copies, modification, alteration, enhancement, and/or distribution of this document are not permitted without the express permission of the Heart Rhythm Society. Instructions for obtaining permission are located at https://www.elsevier.com/about/ourbusiness/policies/copyright/permissions. This article has been copublished in Heart Rhythm, Europace, and the Journal of Arrhythmia. Correspondence: Heart Rhythm Society, 1325 G Street NW, Suite 400, Washington, DC 20005. E-mail address: clinicaldocs@hrsonline.org.

3 Libin Cardiovascular Institute of Alberta, University of Calgary, Calgary, Canada

4 Cleveland Clinic, Cleveland, OH, USA 
Document Reviewers: Serge Boveda, MD, PhD; Michael R. Gold, MD, PhD, FHRS; Roberto Keegan, MD; Valentina Kutyifa, MD, PhD, FHRS, FESC, FACC; Chu-Pak Lau, MD, FHRS, CCDS; Mark A. McGuire, MBBS, PhD; Siva K. Mulpuru, MD, FHRS, CCDS; David J. Slotwiner, MD, FHRS; William Uribe, MD, MBA, FHRS.

\section{TABLE OF CONTENTS}

Abstract. In this issue

Manufacturer-Specific Translation of ICD Programming Recommendations: Abbott (Formerly St. Jude Medical).... .In this issue

Manufacturer-Specific Translation of ICD Programming Recommendations: BIOTRONIK................. In this issue Manufacturer-Specific Translation of ICD Programming Recommendations: Boston Scientific. ..In this issue
Manufacturer-Specific Translation of ICD Programming Recommendations: Medtronic..................... In this issue Manufacturer-Specific Translation of ICD Programming Recommendations: MicroPort CRM (Formerly LivaNova and Sorin Group)..............................In this issue Appendix 1 Author disclosure table................In this issue Appendix 2 Reviewer disclosure table..............In this issue 


\section{Manufacturer-specific translation of ICD programming recommendations ${ }^{\ddagger}$}

*The manufacturer-specific programming settings/choices set forth below are based on a compilation of clinical expertise and clinical trial data as reported in the 2015 HRS/EHRA/ APHRS/SOLAECE Expert Consensus Statement on Optimal Implantable Cardioverter-Defibrillator Programming and Testing, of which this Appendix B is a part. These recommended settings/choices represent a diligent and good faith effort on the part of the writing committee to translate the consensus statement recommendations to device settings/choices for the four specified clinical issues/implantable cardioverterdefibrillator (ICD) therapies where the writing committee considered that there was sufficient consensus and supporting data to make recommendations intended to improve the safety, morbidity, and mortality profile of patients with these clinical issues/ICD therapies. They are the recommendations of the writing committee only. They do not represent the position or recommendations of HRS, EHRA, LAHRS (formerly SOLAECE), or APHRS, nor are they the manufacturer's nominal settings or the precise programming tested during clinical trials of these devices, nor are they necessarily the settings/ choices that would be recommended by the manufacturer. These recommended settings/choices are not applicable in all circumstances. As stated in the Introduction to the consensus statement, "The care of individual patients must be provided in context of their specific clinical condition and the data available on that patient." Each treating physician must carefully consider the circumstances of their individual patient and determine whether these recommended settings/choices are appropriate to their patient's circumstances.

\subsection{Abbott (Formerly St. Jude Medical) *Settings that are not nominal are marked with an asterisk}

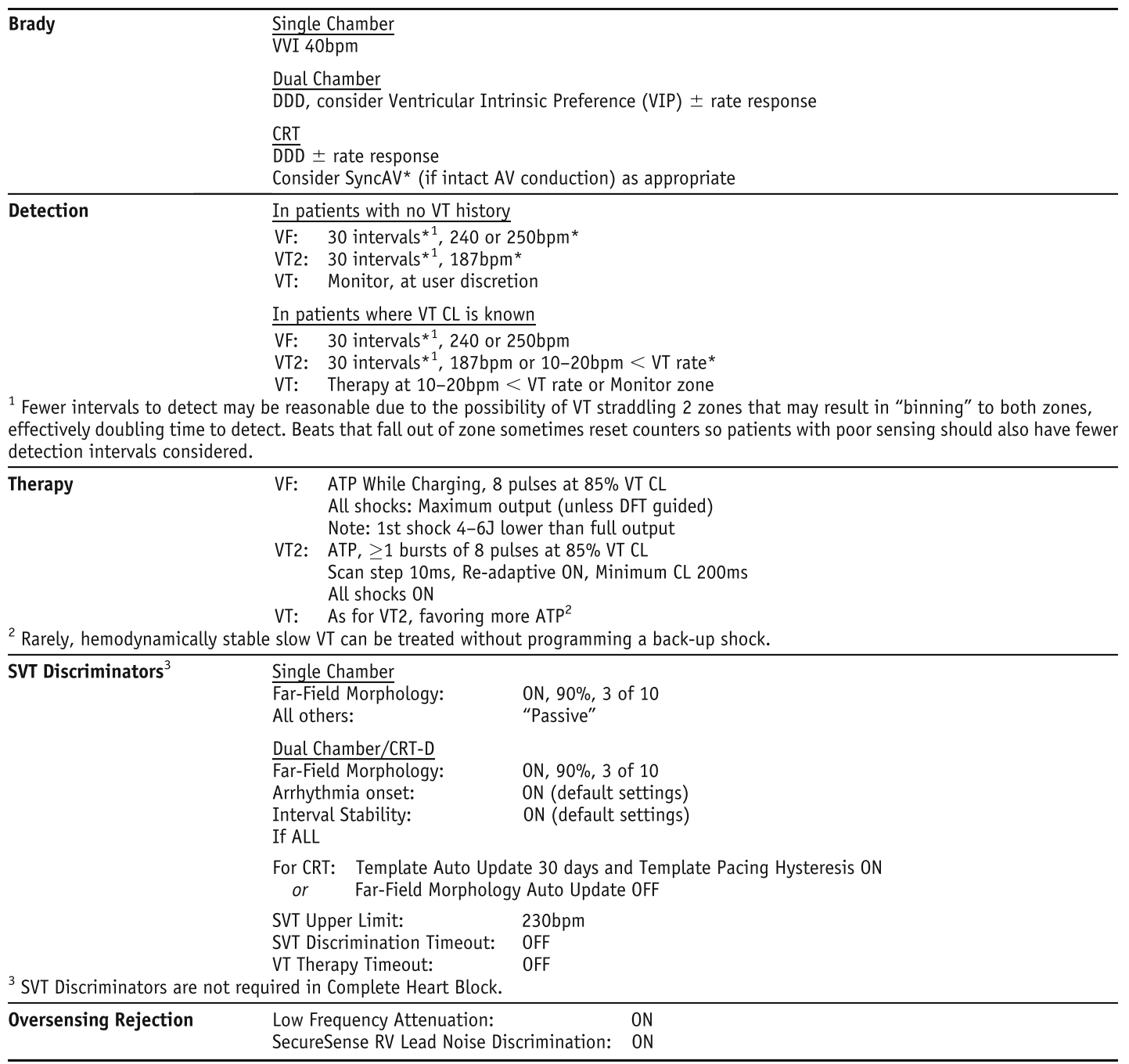




\section{Manufacturer-specific translation of ICD programming recommendations ${ }^{\ddagger}$}

*The manufacturer-specific programming settings/choices set forth below are based on a compilation of clinical expertise and clinical trial data as reported in the 2015 HRS/EHRA/ APHRS/SOLAECE Expert Consensus Statement on Optimal Implantable Cardioverter-Defibrillator Programming and Testing, of which this Appendix B is a part. These recommended settings/choices represent a diligent and good faith effort on the part of the writing committee to translate the consensus statement recommendations to device settings/choices for the four specified clinical issues/implantable cardioverterdefibrillator (ICD) therapies where the writing committee considered that there was sufficient consensus and supporting data to make recommendations intended to improve the safety, morbidity, and mortality profile of patients with these clinical issues/ICD therapies. They are the recommendations of the writing committee only. They do not represent the position or recommendations of HRS, EHRA, LAHRS (formerly SOLAECE), or APHRS, nor are they the manufacturer's nominal settings or the precise programming tested during clinical trials of these devices, nor are they necessarily the settings/ choices that would be recommended by the manufacturer. These recommended settings/choices are not applicable in all circumstances. As stated in the Introduction to the consensus statement, "The care of individual patients must be provided in context of their specific clinical condition and the data available on that patient." Each treating physician must carefully consider the circumstances of their individual patient and determine whether these recommended settings/choices are appropriate to their patient's circumstances.

\subsection{BIOTRONIK \\ *Settings that are not nominal are marked with an asterisk}

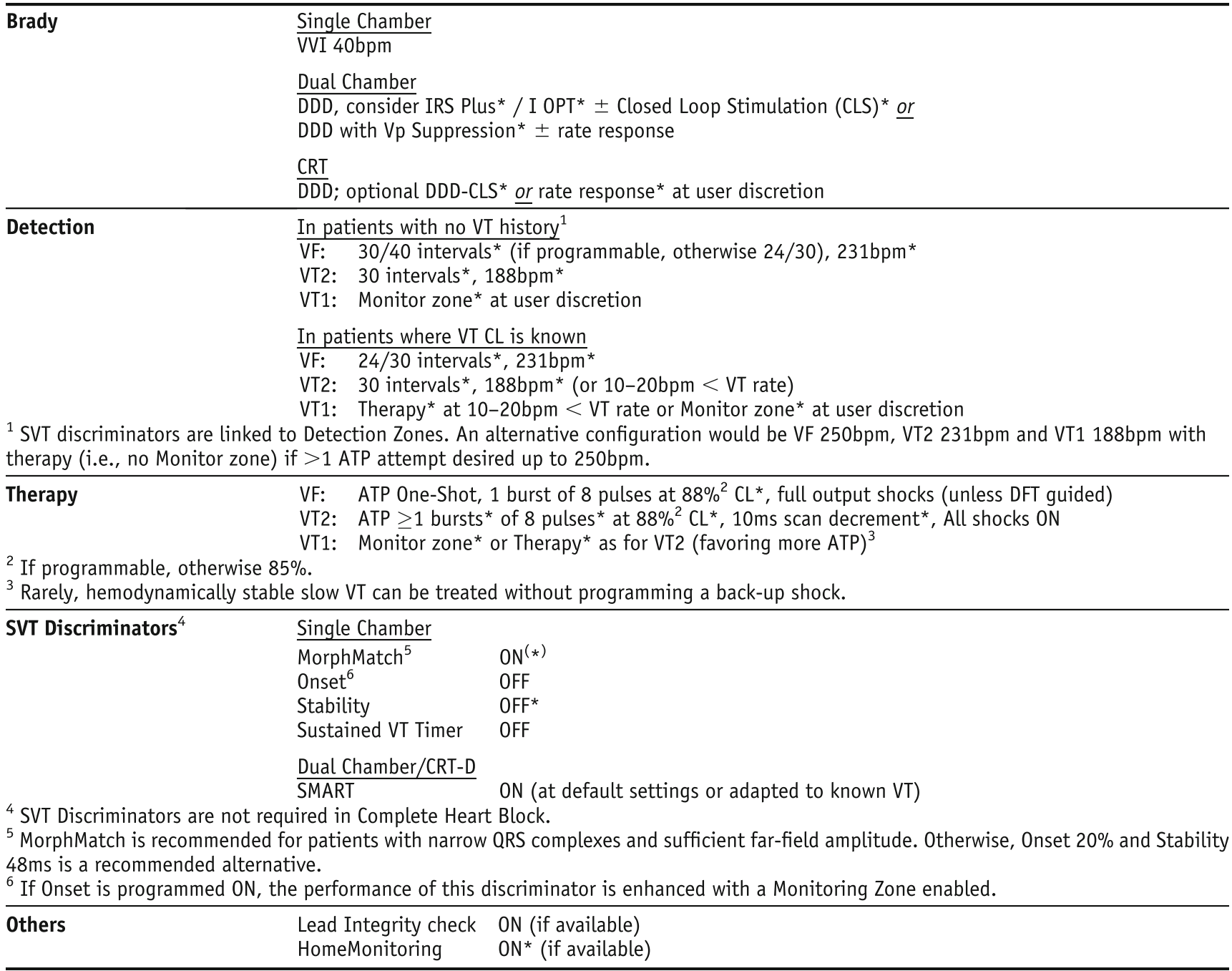




\section{Manufacturer-specific translation of ICD programming recommendations ${ }^{\ddagger}$}

*The manufacturer-specific programming settings/choices set forth below are based on a compilation of clinical expertise and clinical trial data as reported in the 2015 HRS/EHRA/APHRS/ SOLAECE Expert Consensus Statement on Optimal Implantable Cardioverter-Defibrillator Programming and Testing, of which this Appendix B is a part. These recommended settings/choices represent a diligent and good faith effort on the part of the writing committee to translate the consensus statement recommendations to device settings/choices for the four specified clinical issues/ implantable cardioverter-defibrillator (ICD) therapies where the writing committee considered that there was sufficient consensus and supporting data to make recommendations intended to improve the safety, morbidity, and mortality profile of patients with these clinical issues/ICD therapies. They are the recommendations of the writing committee only. They do not represent the position or recommendations of HRS, EHRA, LAHRS (formerly SOLAECE), or APHRS, nor are they the manufacturer's nominal settings or the precise programming tested during clinical trials of these devices, nor are they necessarily the settings/choices that would be recommended by the manufacturer. These recommended settings/choices are not applicable in all circumstances. As stated in the Introduction to the consensus statement, "The care of individual patients must be provided in context of their specific clinical condition and the data available on that patient." Each treating physician must carefully consider the circumstances of their individual patient and determine whether these recommended settings/choices are appropriate to their patient's circumstances.

\subsection{Boston Scientific \\ *Settings that are not nominal are marked with an asterisk}

\begin{tabular}{|c|c|}
\hline \multirow[t]{3}{*}{ Brady } & $\frac{\text { Single Chamber }}{\text { VVI, 40bpm* }}$ \\
\hline & $\frac{\text { Dual Chamber }}{\mathrm{DDD} \text {, consider RYTHMIQ* or AV Search }+^{*} \pm \text { rate response }}$ \\
\hline & $\begin{array}{l}\frac{\mathrm{CRT}}{\mathrm{DDD}} \pm \text { rate response } \\
\text { Consider Smart Delay optimization of AV delays }\end{array}$ \\
\hline \multirow[t]{3}{*}{ Detection } & $\begin{array}{l}\text { In patients with no VT history } \\
\text { Option } 1 \text { - delayed therapy } \\
\text { VF: } 8 \text { of } 10 \text { intervals plus } 5 \text {-second duration }{ }^{*}, 250 \mathrm{bpm}^{*} \\
\text { VT: } 8 \text { of } 10 \text { intervals plus } 12 \text {-second duration*, } 185 \mathrm{bpm}^{*} \\
\text { VT-1: Monitor, at user discretion }\end{array}$ \\
\hline & $\begin{array}{l}\text { Option } 2 \text { - high-rate therapy } \\
\text { VF: } 8 \text { of } 10 \text { intervals plus } 2.5 \text {-second duration*, 200bpm* } \\
\text { VT-1: Monitor, at user discretion }\end{array}$ \\
\hline & $\begin{array}{l}\text { In patients where VT cycle length is known } \\
\text { VF: } 5 \text {-second duration }{ }^{*}, 250 \mathrm{bpm}^{*} \\
\text { VT: } 12 \text {-second duration* } 185 \mathrm{bpm}^{*} \text { or } 10-20 \mathrm{bpm}<\mathrm{VT} \text { rate } \\
\text { VT-1: Monitor Zone or Therapy at } \geq 12 \text {-second duration }{ }^{*}, 10-20 \mathrm{bpm}<\mathrm{VT} \text { rate }\end{array}$ \\
\hline $\begin{array}{l}\text { Therapy } \\
{ }^{1} \text { Rarely, hemodynamical }\end{array}$ & $\begin{array}{l}\text { VF: QuickConvert ON to } 300 \mathrm{bpm}^{*} \text { (if available) } \\
\text { All shocks: Maximum output (unless DFF guided) } \\
\text { VT: ATP-1: Scan, } \geq 1 \text { bursts, } 8 \text { pulses }{ }^{*} \text { at } 84 \%^{*} \text { coupling interval and cycle } \\
\text { length (Minimum } 200 \mathrm{~ms}^{*} \text { ), } 10 \mathrm{~ms} \text { decrement* } \\
\text { ATP-2: OFF* } \\
\text { All shocks: ON } \\
\text { VT-1: As for VT, favoring more ATP }{ }^{1} \\
\text { e slow VT can be treated without programming a back-up shock. }\end{array}$ \\
\hline \multirow[t]{2}{*}{ SVT Discriminators ${ }^{2}$} & $\frac{\text { ICD }}{\text { RhythmID: ON }}$ \\
\hline & $\begin{array}{l}\frac{\text { CRT-D }}{\text { Onset/Stability: ON or RhythmID: ON* }} \\
\text { Sustained Rate Duration (SRD): OFF* } \\
\text { SVT Discriminators apply only up to } 230 \mathrm{bpm} \\
\text { uired in Complete Heart Block. }\end{array}$ \\
\hline Oversensing Rejection & Nonphysiological Signal Detected: ON (Latitude) \\
\hline Others & $\begin{array}{l}\text { Turn on "Beep When Out-of-Range" Daily Lead Measurements* } \\
\text { RV Pacing Impedance Abrupt Change alert ON (Latitude) } \\
\text { Single Chamber: Consider \%RV pacing alert ON (Latitude) } \\
\text { Dual Chamber: Consider \%RV pacing alert in non-AVB patients ON (Latitude) } \\
\text { CRT-D: Consider CRT \% pacing alert ON (Latitude) }\end{array}$ \\
\hline $\begin{array}{l}\text { SUBCUTANEOUS ICD } \\
\text { Settings: }\end{array}$ & $\begin{array}{l}\text { Shock Zone: } \geq 230 \mathrm{bpm} \\
\text { Conditional Zone: } \geq 200 \mathrm{bpm} \text { or } 10-20 \mathrm{bpm}<\mathrm{VT} \mathrm{CL} \text { (if known) } \\
\text { Consider post-shock pacing ON }\end{array}$ \\
\hline
\end{tabular}




\section{Manufacturer-specific translation of ICD programming recommendations ${ }^{\ddagger}$}

*The manufacturer-specific programming settings/choices set forth below are based on a compilation of clinical expertise and clinical trial data as reported in the 2015 HRS/EHRA/APHRS/ SOLAECE Expert Consensus Statement on Optimal Implantable Cardioverter-Defibrillator Programming and Testing, of which this Appendix B is a part. These recommended settings/choices represent a diligent and good faith effort on the part of the writing committee to translate the consensus statement recommendations to device settings/choices for the four specified clinical issues/ implantable cardioverter-defibrillator (ICD) therapies where the writing committee considered that there was sufficient consensus and supporting data to make recommendations intended to improve the safety, morbidity, and mortality profile of patients with these clinical issues/ICD therapies. They are the recommendations of the writing committee only. They do not represent the position or recommendations of HRS, EHRA, LAHRS (formerly SOLAECE), or APHRS, nor are they the manufacturer's nominal settings or the precise programming tested during clinical trials of these devices, nor are they necessarily the settings/choices that would be recommended by the manufacturer. These recommended settings/choices are not applicable in all circumstances. As stated in the Introduction to the consensus statement, "The care of individual patients must be provided in context of their specific clinical condition and the data available on that patient." Each treating physician must carefully consider the circumstances of their individual patient and determine whether these recommended settings/choices are appropriate to their patient's circumstances.

\subsection{Medtronic}

*Settings that are not nominal are marked with an asterisk

\begin{tabular}{|c|c|c|}
\hline \multirow[t]{3}{*}{ Brady } & \multicolumn{2}{|l|}{$\frac{\text { Single Chamber }}{\text { VVI 40bpm }}$} \\
\hline & \multicolumn{2}{|c|}{$\frac{\text { Dual Chamber }}{\text { DDD, consider Managed Ventricular Pacing }(M V P ; A A I \leftrightarrow D D D)} \pm$ rate response } \\
\hline & \multicolumn{2}{|c|}{$\begin{array}{l}\frac{\mathrm{CRT}}{\mathrm{DDD}} \pm \text { rate response } \\
\text { Patient with intact } \mathrm{AV} \text { conduction and } \mathrm{LBBB}-\text { Consider Adaptive BiV \& } \mathrm{LV} *\end{array}$} \\
\hline \multirow[t]{2}{*}{ Detection } & $\begin{array}{l}\text { In patients with no V } \\
\text { VF: } \\
\text { FVT: } \\
\text { VT: } \\
\text { VT Monitor: }\end{array}$ & $\begin{array}{l}\text { Thistory } \\
30 / 40 \text { intervals, } 188 \mathrm{bpm} \\
\mathrm{OFF}^{1} \\
\text { OFF } \\
\text { User discretion }\end{array}$ \\
\hline & $\begin{array}{l}\text { In patients where VT } \\
\text { VF: } \\
\text { FVT: } \\
\text { VT: } \\
\text { VT Monitor: } \\
\text { ging in the VF zone ach } \\
\text { hence, lower NID as pe }\end{array}$ & $\begin{array}{l}\mathrm{CL} \text { is known } \\
30 / 40 \text { intervals, } 188 \mathrm{bpm} \\
\mathrm{OFF}^{1} \\
24^{*} \text { intervals }{ }^{2}, 10-20 \mathrm{bpm}<\mathrm{VT} \text { rate } \\
\text { User discretion } \\
\text { hieves similar functionality as use of the FVT zone. Multi-zone programming using FV } \\
\text { PainFree SST data. }\end{array}$ \\
\hline $\begin{array}{l}\text { Therapy } \\
{ }^{3} \text { Rarely, hemodynamica }\end{array}$ & \multicolumn{2}{|c|}{$\begin{array}{ll}\text { VF: } & \text { ATP Before* Charging; ChargeSaver ON All shocks: Full output shocks (unless DFT guided) } \\
\text { VT (if 0N): } & \text { R×1: ATP, } \geq 1 \text { bursts of } 8 \text { pulses at } 88 \% \text { VT CL, } 10 \mathrm{~ms} \text { Decrement } \\
& \text { R×2-6: All Shocks } 0 N^{3}\end{array}$} \\
\hline \multirow[t]{2}{*}{ SVT Discriminators ${ }^{4}$} & $\begin{array}{l}\text { Single Chamber } \\
\text { Wavelet: } \\
\text { Limit: } \\
\text { Stability: } \\
\text { Onset: }\end{array}$ & $\begin{array}{l}\text { ON } \\
260 \mathrm{~ms}(230 \mathrm{bpm}) \\
\text { OFF } \\
\text { OFF }\end{array}$ \\
\hline & $\begin{array}{l}\text { Dual Chamber/CRT-D } \\
\text { PR Logic: } \\
\text { Wavelet: } \\
\text { SVT Limit: } \\
\text { Stability: } \\
\text { Onset: } \\
\text { dired in Complete Hear }\end{array}$ & $\begin{array}{l}\text { ON (Other 1:1 OFF until lead stabilized at } \sim 3 \text { months) } \\
\text { ON (if available) } \\
260 \mathrm{~ms}(230 \mathrm{bpm}) \\
\text { OFF } \\
\text { OFF } \\
\text { t Block. }\end{array}$ \\
\hline Oversensing Rejection & $\begin{array}{l}\text { Lead Integrity Alert: } \\
\text { T-wave Oversensing: } \\
\text { RV Lead Noise: }\end{array}$ & $\begin{array}{l}\text { ON } \\
\text { ON (if available) } \\
\text { ON* without timeout (if available) }\end{array}$ \\
\hline
\end{tabular}




\section{Manufacturer-specific translation of ICD programming recommendations ${ }^{\ddagger}$}

${ }^{*}$ The manufacturer-specific programming settings/choices set forth below are based on a compilation of clinical expertise and clinical trial data as reported in the 2015 HRS/EHRA/ APHRS/SOLAECE Expert Consensus Statement on Optimal Implantable Cardioverter-Defibrillator Programming and Testing, of which this Appendix B is a part. These recommended settings/choices represent a diligent and good faith effort on the part of the writing committee to translate the consensus statement recommendations to device settings/choices for the four specified clinical issues/implantable cardioverterdefibrillator (ICD) therapies where the writing committee considered that there was sufficient consensus and supporting data to make recommendations intended to improve the safety, morbidity, and mortality profile of patients with these clinical issues/ICD therapies. They are the recommendations of the writing committee only. They do not represent the position or recommendations of HRS, EHRA, LAHRS (formerly SOLAECE), or APHRS, nor are they the manufacturer's nominal settings or the precise programming tested during clinical trials of these devices, nor are they necessarily the settings/ choices that would be recommended by the manufacturer. These recommended settings/choices are not applicable in all circumstances. As stated in the Introduction to the consensus statement, "The care of individual patients must be provided in context of their specific clinical condition and the data available on that patient." Each treating physician must carefully consider the circumstances of their individual patient and determine whether these recommended settings/choices are appropriate to their patient's circumstances.

\subsection{MicroPort CRM (Formerly LivaNova and Sorin Group) *Settings that are not nominal are marked with an asterisk}

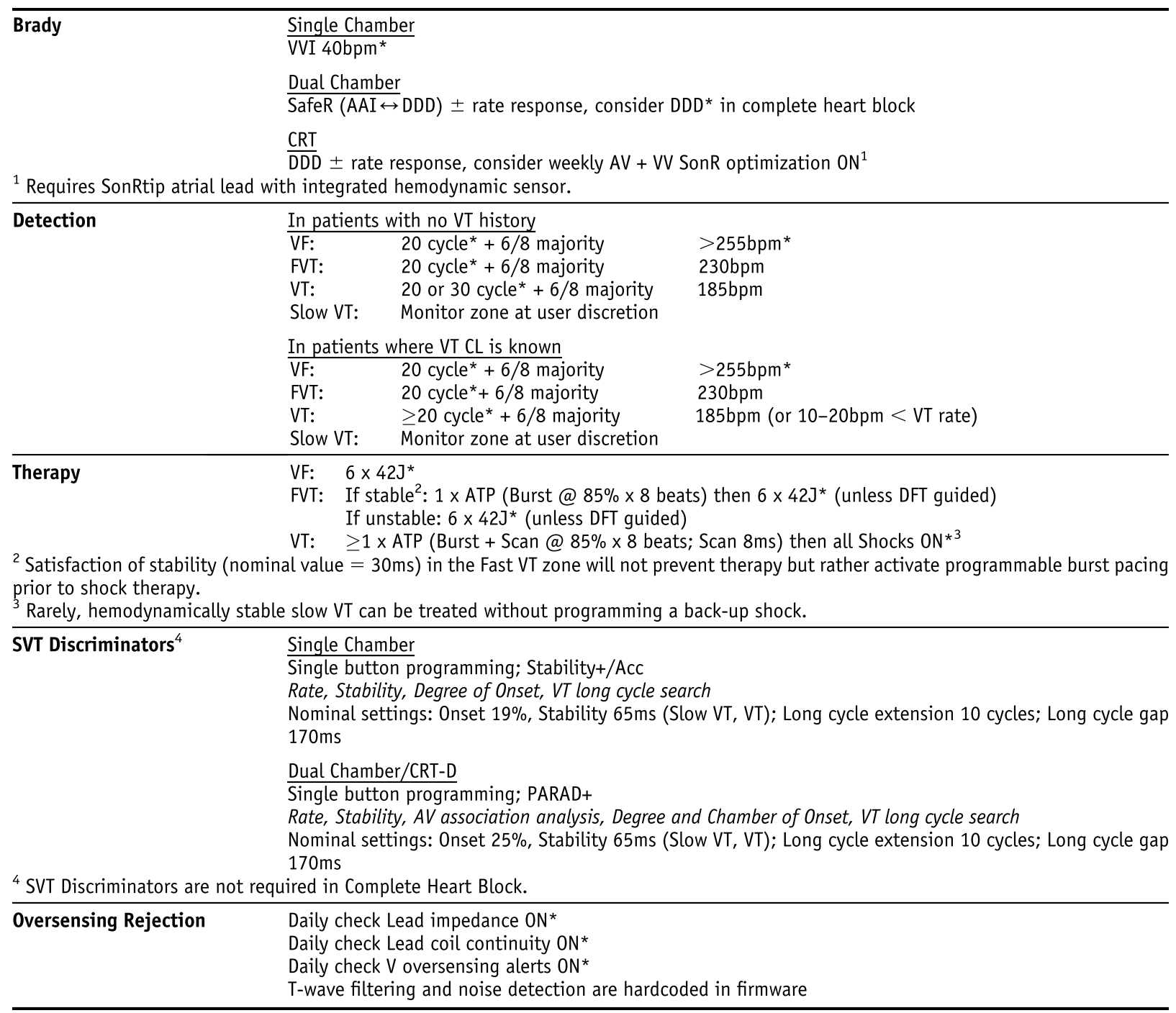




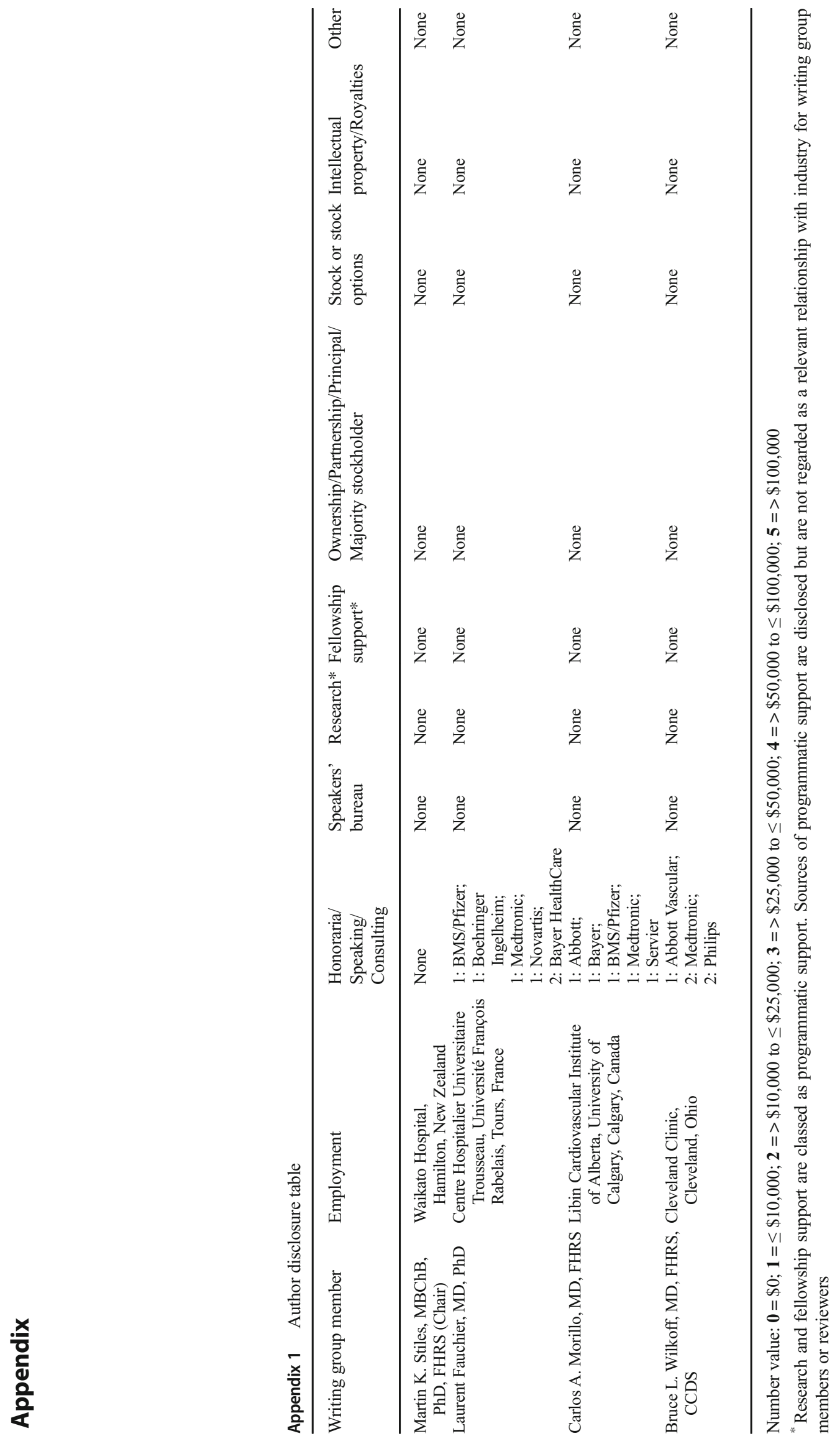




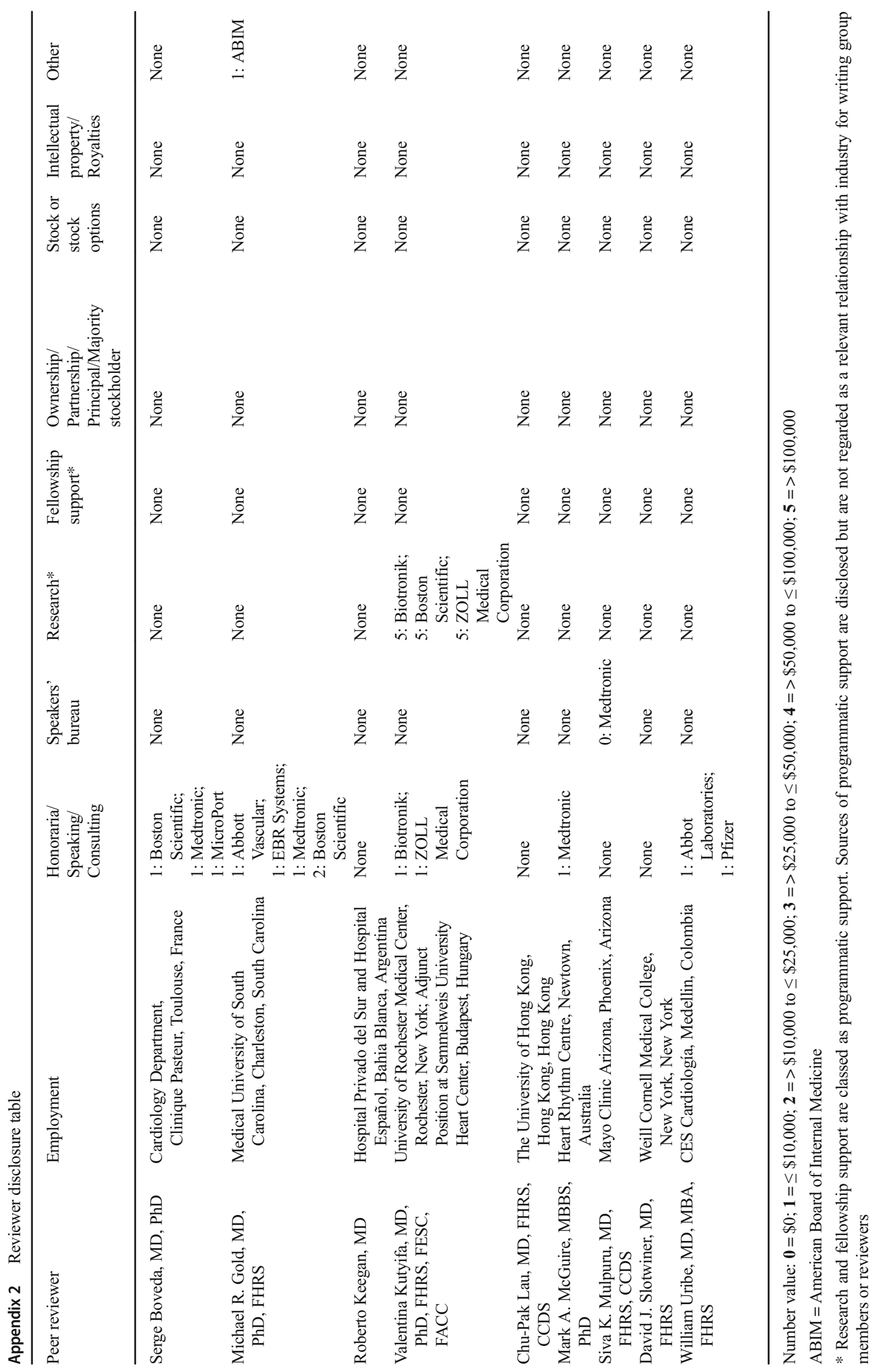


Open Access This article is licensed under a Creative Commons Attribution 4.0 International License, which permits use, sharing, adaptation, distribution and reproduction in any medium or format, as long as you give appropriate credit to the original author(s) and the source, provide a link to the Creative Commons licence, and indicate if changes were made. The images or other third party material in this article are included in the article's Creative Commons licence, unless indicated otherwise in a credit line to the material. If material is not included in the article's Creative Commons licence and your intended use is not permitted by statutory regulation or exceeds the permitted use, you will need to obtain permission directly from the copyright holder. To view a copy of this licence, visit http://creativecommons.org/licenses/by/4.0/. 